\title{
$A$ rapid and sensitive bioassay to measure bone morphogenetic protein activity Lior Zilberberg ${ }^{1}$, Peter ten Dijke ${ }^{2}$, Lynn Y Sakai ${ }^{3}$ and Daniel B Rifkin*1,4
}

\begin{abstract}
Address: ${ }^{1}$ Department of Cell Biology, New York University School of Medicine, New York, New York 10016, USA, ${ }^{2}$ Department of Molecular and Cell Biology, Leiden University Medical Center, 2300 RC Leiden, The Netherlands, ${ }^{3}$ Department of Biochemistry and Molecular Biology, Oregon Health \& Science University and Shriners Hospital for Children, Portland, OR 97239, USA and ${ }^{4}$ Department of Medicine, New York University School of Medicine, New York, New York 10016, USA
\end{abstract}

Email: Lior Zilberberg - zilbel01@med.nyu.edu; Peter ten Dijke - p.ten_dijke@lumc.nl; Lynn Y Sakai - lys@shcc.org; Daniel B Rifkin* - rifkid01@med.nyu.edu

* Corresponding author

Published: 19 September 2007

BMC Cell Biology 2007, 8:4| doi:|0.||86/|47|-2|2|-8-4|
Received: 9 March 2007

Accepted: 19 September 2007

This article is available from: http://www.biomedcentral.com/|47|-2|2|/8/4|

(c) 2007 Zilberberg et al; licensee BioMed Central Ltd.

This is an Open Access article distributed under the terms of the Creative Commons Attribution License (http://creativecommons.org/licenses/by/2.0), which permits unrestricted use, distribution, and reproduction in any medium, provided the original work is properly cited.

\begin{abstract}
Background: Bone morphogenetic proteins (BMPs) are members of the TGF-beta superfamily and were originally identified as proteins that induce ectopic bone formation. BMPs were shown subsequently to be involved in several biological processes during development and in adult tissues through the regulation of the growth, differentiation and apoptosis of various cell types. An alkaline phosphatase (ALP)-based assay is the most widely used assay to evaluate BMP activity. However, the ALP assay is not rapid and not sensitive enough to measure BMP activity at physiological concentrations. In this paper, we describe a highly sensitive, rapid, and specific cell-based assay for the quantification of BMP activity.
\end{abstract}

Results: Two cells lines, $\mathrm{C} 2 \mathrm{Cl} 2$ and $\mathrm{HepG} 2$ were stably transfected with a reporter plasmid consisting of BMP-responsive elements from the IdI promoter fused to a luciferase reporter gene. Exposure of cells containing this construct to BMPs induces the expression of luciferase, which can be quantified with a luminometer. The bioassay is specific for BMPs and can detect BMP-4 activity at a concentration as low as 3 pM. Related family members, such as TGF-betal, TGF-beta2 and TGF-beta3, do not induce the reporter gene.

Conclusion: The assay is rapid (less than 24 hours) and can be used, as described in this paper, to measure BMP activity in complex solutions and in cell culture in a simple and efficient way.

\section{Background}

Bone morphogenic proteins (BMPs) are members of the transforming growth factor beta (TGF- $\beta$ ) superfamily that consists of a number of structurally related polypeptides that control a broad array of cellular processes, including cell proliferation, apoptosis and differentiation $[1,2]$. Although BMPs originally were identified as proteins that induced formation of bone when implanted into the muscle of adult rats $[3,4]$, BMPs also play crucial roles in dorsoventral patterning of the mesoderm, neural patterning, skeletal development, and limb formation [5]. Altered BMP signaling pathways are associated with several human diseases including arthritis, osteoporosis, kidney diseases, cancer and pulmonary hypertension [6-10]. 
BMPs are synthesized as precursor proteins. After dimerization, the precursor molecules are proteolytically cleaved within the cell by proprotein convertases at the multibasic motif RXXR to yield the active, carboxy-terminal mature protein dimer [11-13]. BMPs exert their biological activity through combinations of type I and type II serine/threonine kinase receptors. Three distinct BMP type I receptors, i.e. activin receptor-like kinase (ALK)-2, ALK3 (also termed BMPRIA) and ALK6 (BMPRIB) and three distinct type II receptors, i.e. BMP type II receptor (BMPRII) and two activin type II receptors (ActR-IIA and ActR-IIB) have been identified [1]. Upon ligand binding, the type II receptors phosphorylate the type I receptor, which in turn initiates the downstream signaling process through phosphorylation of BMP-specific receptor-regulated Smads (RSmads), i.e. Smad1, Smad5 or Smad8 [14-16]. R-Smads form a complex with Smad4 and translocate into the nucleus where the complex regulates the transcription of various target genes through its association with other transcription factors [17]. In contrast, TGF- $\beta$ and activin signaling pathways recruit Smad2 and Smad3, which can also form heteromeric complexes with Smad4.

In addition to the tissue-specific expression of BMPs and their surface receptors, the biological activity of BMPs is regulated by a number of extracellular inhibitory molecules, such as chordin, noggin and follistatin [18]. Moreover, BMP signaling can be modulated by cross-talk with other pathways. TGF- $\beta$ and BMP can modulate the activity of each other through competition for the interaction of their respective R-Smad with Smad4 or through activation of inhibitor Smads (I-Smads) $[19,20]$.

The biological effects of BMPs have been used to develop quantitative bioassays. To date, alkaline phosphatase activity, a marker of osteoblast differentiation, measured in mesenchymal cells upon BMP stimulation, is the invitro assay most widely used among the research community to evaluate BMP activity [21]. However, the response in this assay is slow, usually taking between two to five days, and the assay is not sensitive enough to measure the low BMP concentrations generated in many biological systems.

Here we describe the development of a rapid and highly sensitive cell-based assay to measure BMP activities in different biological contexts. C2C12 mouse mesenchymal cells and HepG2 human hepatoma cells were stably transfected with a construct consisting of a BMP/Smaddependent specific enhancer derived from the Id1 promoter and fused to a luciferase reporter gene [22]. Through screening and cloning, we generated two stable cell lines, C2C12BRA and HepG2BRA, which can measure BMP activity with high sensitivity and in various biological situations.

\section{Results \\ Expression of BMP and BMPRs in the HepG2BRA and C2CI2BRA}

C2C12 mouse myoblast and HepG2 human hepatoma cell lines, which are known to respond to BMPs, were stably transfected with the BRE-Luc construct. This construct contains regions of the mouse Id1 promoter, which are important for the induction of Id 1 transcription by BMPs, fused to a luciferase reporter gene. After cloning the transfected $\mathrm{C} 2 \mathrm{C} 12$ and HepG2 colonies, cells from C2C12 clone 9 (named C2C12BRA) and HepG2 clone 15 (named HepG2BRA) were found to be the most sensitive upon stimulation with recombinant BMP-4 (data not shown). These clones were used for all subsequent experiments.

To obtain a comprehensive picture of the repertoire of BMPs and BMPRs expressed by C2C12BRA and HepG2BRA cells, we analyzed the expression of mRNAs coding for BMPs and BMPRs. Total RNA was isolated from C2C12BRA and HepG2BRA cells and subjected to RTPCR. HepG2BRA cells expressed the mRNA for BMP-4 (Fig. 1A). No PCR products were observed for BMP-2, BMP-6 and BMP-7. We next analyzed the expression of mRNA coding for the three type I receptors (ALK2, ALK3 and ALK6) and the three type II receptors (ActR-IIA, ActRIIB and BMPRII). C2C12BRA cells express ALK2, BMPRII and ActR-IIA mRNA (Fig. 1B). Trace levels of ALK3 and ActR-IIB were detected, whereas no expression of ALK6 was observed. HepG2BRA cells express ALK2, BMPRII and ActR-IIB mRNA. Trace levels of ALK3 were detected, whereas no PCR products were obtained for ALK6 and ActR-IIA (Fig. 1B).

\section{Dose-dependent induction of the BRE-Luc contruct by BMPs}

HepG2BRA and C2C12BRA cells were assayed for the induction of luciferase expression using a broad range of BMP-2, BMP-4, BMP-6 and BMP-7 concentrations (Fig. 2). HepG2BRA and C2C12BRA cells demonstrated equivalent dose-responses when stimulated with BMP-2 $\left(\mathrm{ED}_{50}\right.$ 0.25-0.35 nM; sensitivity 40-80 pM) (Fig. 2A) and BMP-6 (ED E0 $_{0} \sim 0.2-0.4 \mathrm{nM}$; sensitivity 40-150 pM), but a different dose-response curve for BMP-4 and BMP-7 (Fig. $2 \mathrm{~B}, 2 \mathrm{C}$ and $2 \mathrm{D}$, respectively). BMP-4 was the most potent inducer of luciferase activity with an $\mathrm{ED}_{50}$ of approximately 10 pM and 50 pM for C2C12BRA and HepG2BRA cells, respectively. BMP-7 was the least potent inducer of luciferase expression with an $\mathrm{ED}_{50}$ of approximately 0.5 $\mathrm{nM}$ and a sensitivity between 0.1 to $0.15 \mathrm{nM}$ for the HepG2BRA reporter assay. The dependence of the assay for the ligand was shown for BMP-4 by inclusion of a neutralizing antibody for BMP-4 (MAB 757) that blocked the luciferase response (data not shown). 


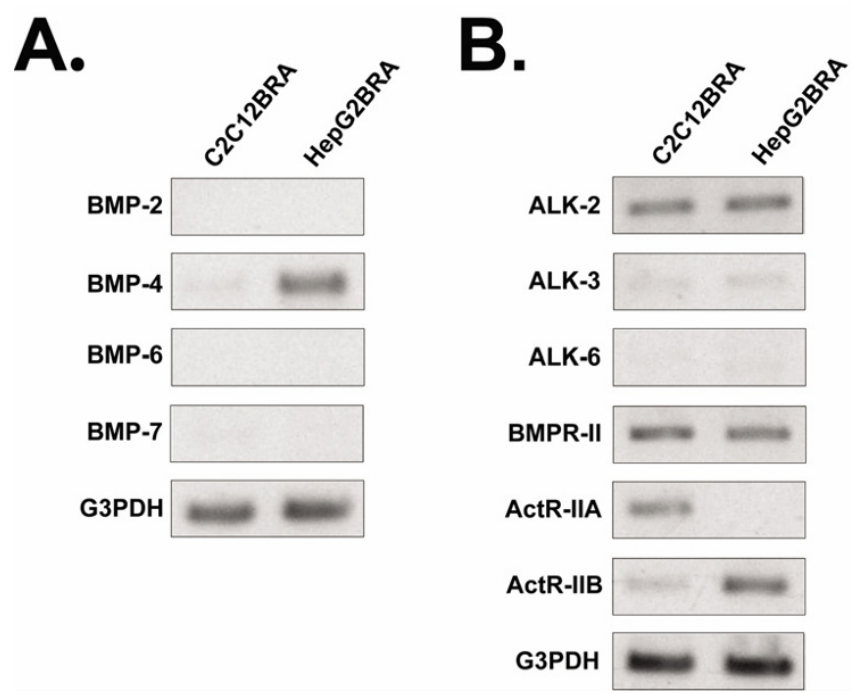

Figure I

Expression of BMP and BMPRs in HepG2BRA and C2CI2BRA cells. Total RNA from C2CI2BRA and HepG2BRA cells was isolated and used as a template for the reverse transcriptase-polymerase chain reaction (RT-PCR) to examine the expression of BMP and BMPRs. G3PDH gene expression was used as an internal control. PCR products were separated in I\% agarose gel and visualized after ethidium bromide staining. (A) Representative RT-PCR analysis of total RNA using specific primers for BMP-2, BMP-4, BMP-6 and BMP-7. (B) Representative RT-PCR analysis of total RNA using specific primers for BMP type I receptors (ALK2,

ALK3, ALK6) and BMP type II receptors (BMPR-II, ActR-IIA, ActR-IIB). Similar results were obtained in two separate experiments.

\section{Effect of incubation time on luciferase activity}

Next we tested the response of C2C12BRA cells to recombinant BMP-4 using different incubation times and different concentrations of the growth factor. At a concentration of recombinant BMP-4 as low as $3.5 \mathrm{pM}$, the sensitivity of the C2C12BRA cells was equivalent for incubation times of $5 \mathrm{~h}, 10 \mathrm{~h}$ and $15 \mathrm{~h}$ but decreased at an incubation time of $24 \mathrm{~h}$ (Fig. 3). When C2C12BRA cells were stimulated with concentrations above $3.5 \mathrm{pM}$, incubation times between $10 \mathrm{~h}$ and $15 \mathrm{~h}$ were optimal. Shorter or longer incubation times yielded decreased responses (Fig. 3). It is interesting that the luciferase response declined at the longer time points. The reasons for this are unclear but may relate to the kinetics of gene expression and stability of the luciferase.

\section{Specificity of the assay}

Next we investigated the effect of different concentrations of serum on the stimulation of luciferase activity with recombinant BMP-4. The responses of HepG2BRA and C2C12BRA cells differed with respect to serum concentra- tions. The presence of serum impaired the response of HepG2BRA cells at all concentrations of rBMP-4 tested, with a strong decrease in sensitivity with medium containing $10 \%$ FBS and a mild decrease with serum concentrations of $1 \%, 2 \%$ and 5\% (Fig. 4A). With HepG2BRA cells, the luciferase response was best using serum-free medium and BSA added at a final concentration of $0.1 \%$ (DMEMBSA). On the other hand, $10 \%$ serum had only a minor effect on the response of C2C12BRA cells compared to incubation with DMEM-BSA medium (Fig. 4B). At a low BMP-4 concentration ( $7 \mathrm{pM})$, the relative luciferase activity in the presence of $10 \%$ FBS was actually higher compared to that with serum-free medium. Addition of $1 \%$ or $2 \%$ serum shifted the curve downward at all BMP-4 concentrations tested (Fig. 4B).

We also tested the induction of luciferase activity with other members of the TGF- $\beta$ superfamily, such as TGF- $\beta 1$, TGF- $\beta 2$, TGF- $\beta 3$, as well as TGF- $\beta$-unrelated growth factors, such as FGF-2 and VEGF. As shown in Fig. 5, although BMP-4 at $14 \mathrm{pM}$ induced a strong luciferase expression, there was no elevation of luciferase activity when cells were incubated with different isoforms of TGF$\beta$ even at concentration as high as $1 \mathrm{ng} / \mathrm{ml} .10 \mathrm{ng} / \mathrm{ml}$ of bFGF or VEGF did not induce luciferase expression.

It is well established that TGF- $\beta$ and BMP can modulate the activity of each other through cross-talk of their respective pathways [20]. Therefore, we examined whether TGF- $\beta 1$ would affect the induction of luciferase activity by recombinant BMP-4. As shown in Fig. 6A, increasing the concentration of active TGF- $\beta 1$ reduces the luciferase activity induced by BMP-4 with both C2C12BRA and HepG2BRA cells. Similar results were obtained with TGF- $\beta 2$ and TGF- $\beta 3$ (Data not shown). We performed the opposite experiment using TGF- $\beta$-responsive reporter cells (TMLC) that produce luciferase activity in response to TGF- $\beta$ [23]. TMLC were co-stimulated with $250 \mathrm{pg} / \mathrm{ml}$ of TGF- $\beta 1$ and increasing concentrations of BMP-4 (Fig. 6B). Compared to the effect of TGF- $\beta$ on the $\mathrm{BMP}$-responsive reporter cells, BMP-4 had a very slight effect on luciferase activity induced by TGF- $\beta 1$ in TMLC cells even at a concentration as high as $2.5 \mathrm{ng} / \mathrm{ml}$.

\section{Measurement of BMP activity from biological samples}

We tested the BMP assay with conditioned medium from COS cells transiently transfected with either a dorsalin-1 (Ds1-1) or a BMP-4 expression plasmid. Dorsalin is member of the BMP family that regulates dorsoventral patterning of the neural tube. Like BMPs, Dsl-1 induces alkaline phosphatase synthesis in an osteoblast differentiation assay [24]. We found that both Dsl-1- and BMP-4-conditioned medium induced the expression of luciferase, whereas mock conditioned medium had no effect (Fig. 7A). Conditioned medium from 293T cells transfected 
A.
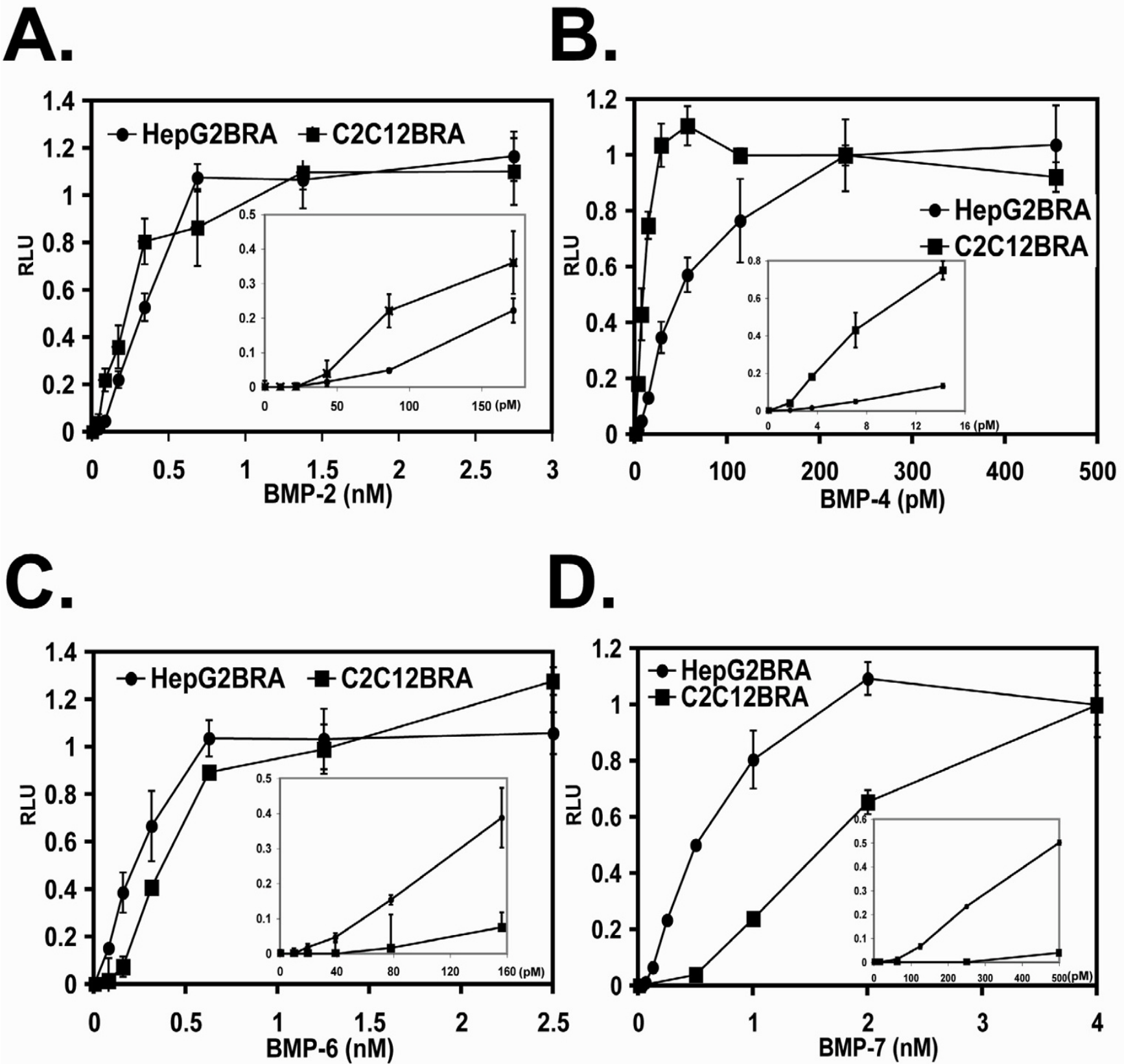

Figure 2

Dose-dependent induction of the BRE-Luc construct by BMPs. C2CI2BRA and HepG2BRA cells were added to 96well plates at $4 \times 10^{3}$ cells per/well and $5 \times 10^{3}$ cells/well, respectively. The reporter cells were incubated with increasing concentrations of the indicated recombinant BMPs in DMEM, $0.1 \%$ BSA. After $15 \mathrm{~h}$ incubation, BMP activity was assessed by measuring luciferase activity in the cell lysates. (A) BMP-2. (B) BMP-4. (C) BMP-6. (D) BMP-7. Background luciferase level in the control sample (no BMP) was subtracted from each of the experimental values. The results are expressed as relative luciferase units (RLU). Each point represents the mean \pm SEM of triplicate wells from I representative experiment. Similar results were obtained in two separate experiments.

with a BMP-7 expression plasmid led to a substantial increase in luciferase activity compared to mock conditioned medium (Fig. 7B). We also cocultured C2C12BRA cells with 293 cells stably transfected with BMP-7 expres- sion plasmid and observed a substantial induction of luciferase activity compared to 293 cells stably transfected with an empty plasmid (Fig. 7C). 


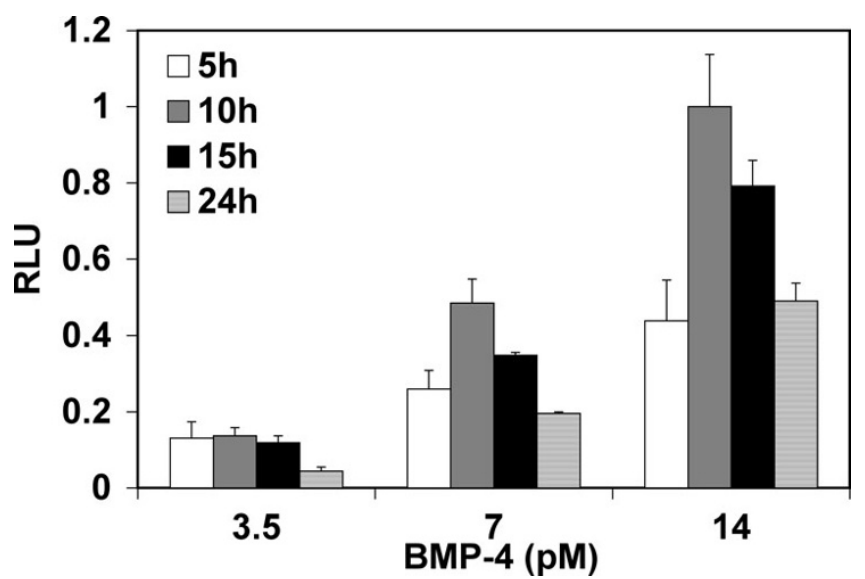

Figure 3

Effect of incubation time on BMP assay sensitivity. C2CI2BRA cells were plated at $4 \times 10^{3}$ cells/well. Recombinant BMP-4 at the indicated concentrations was incubated with the cells for $5,10,15$ or $24 \mathrm{~h}$ prior to assaying for luciferase activity. Background luciferase level in the control sample (no BMP) was subtracted from each of the experimental values. The results are expressed as relative luciferase units (RLU) (the activity with 14 pM of BMP-4 after $10 \mathrm{~h}$ incubation time equals one). Each point represents the mean \pm SEM of triplicate wells from one representative experiment. Similar results were obtained in two separate experiments.

We determined if the reporter assay could be used to detect and quantify BMP activity in biological samples without any enrichment, i.e. concentrating the conditioned medium or overexpressing BMP in cells. For this purpose we measured BMP activity in conditioned medium from lung fibroblasts established from wt and $L t b p-4$ hypomorphic mice (wt and $L t b p-4 \%$ cells, respectively). It was reported that $L t b p-4 \%$ lung fibroblasts express more BMP-4 and less gremlin, a BMP inhibitor, compared to the wt cells [25]. As shown in Fig. 7D, conditioned medium from $L t b p-4 \%$ cells induced luciferase activity more efficiently than wt cells in C2C12BRA cells. The difference between wt and $L t b p-4 \%$ cells corresponded to a BMP-4 concentration of $\sim 3.5 \mathrm{pM}$. We also cocultured C2C12BRA cells with wt and $L t b p-4 \%$ lung fibroblasts and again observed more BMP activity in Ltbp-4\% cells compared to wt cells (Fig. 7D). In fact, the coculture assay yielded almost twice the activity as the assay using conditioned medium. Inclusion in the assay of noggin, an inhibitor of BMP, blocked the BMP activity observed in Ltbp-4\% cells (Fig. 7E).

\section{Discussion}

Currently, the ALP assay is the most widely and routinely used cell-based assay to measure BMP activity. ALP expression is a marker of osteoblast differentiation and BMP-
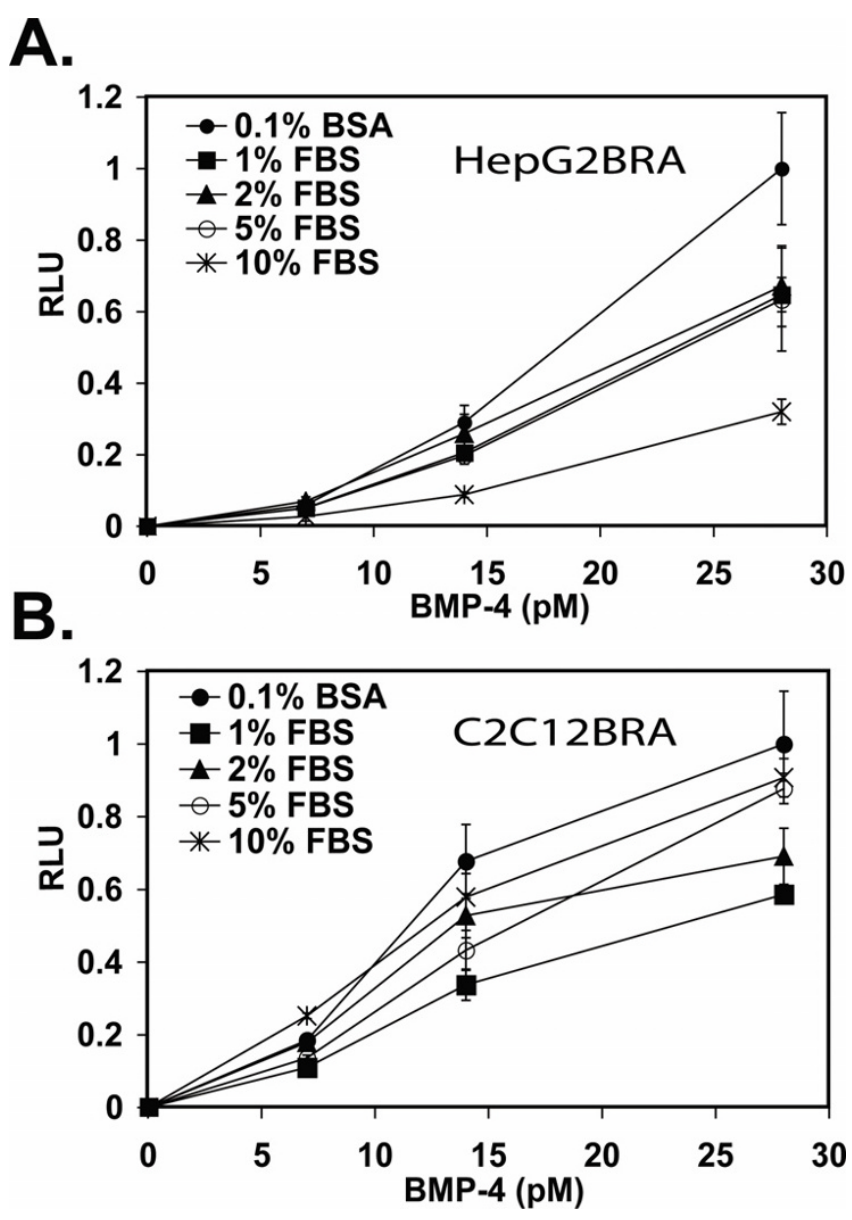

Figure 4

Effect of serum on the assay. HepG2BRA (A) and C2CI2BRA (B) cells were incubated with DMEM containing the indicated concentration of rBMP-4 with $0.1 \%$ BSA or $1 \%$, $2 \%, 5 \%$ and $10 \%$ FBS. Luciferase activity was measured after I $5 \mathrm{~h}$ of incubation. Background luciferase level in the control sample (no BMP) was subtracted from each of the experimental values. The results are expressed as relative luciferase units (RLU). Each point represents the mean \pm SEM of triplicate wells from one representative experiment. Similar results were obtained in two separate experiments.

induced osteogenic differentiation of mesenchymal cells. However, this assay has several drawbacks. The time required to perform the assay is long, usually between two to five days. This assay is not sensitive enough to detect BMP concentrations generated in many biological systems and ALP expression can be affected negatively or positively by a variety of other signaling pathways, such as Sonic hedgehog, FGF-2 or Wnt/beta-catenin [26-28].

In the present paper, we describe the establishment of a highly sensitive and specific assay to measure BMP activity. Two stable cell clones, C2C12BRA and HepG2BRA, were isolated after transfection of $\mathrm{C} 2 \mathrm{C} 12$ and HepG2 cells 


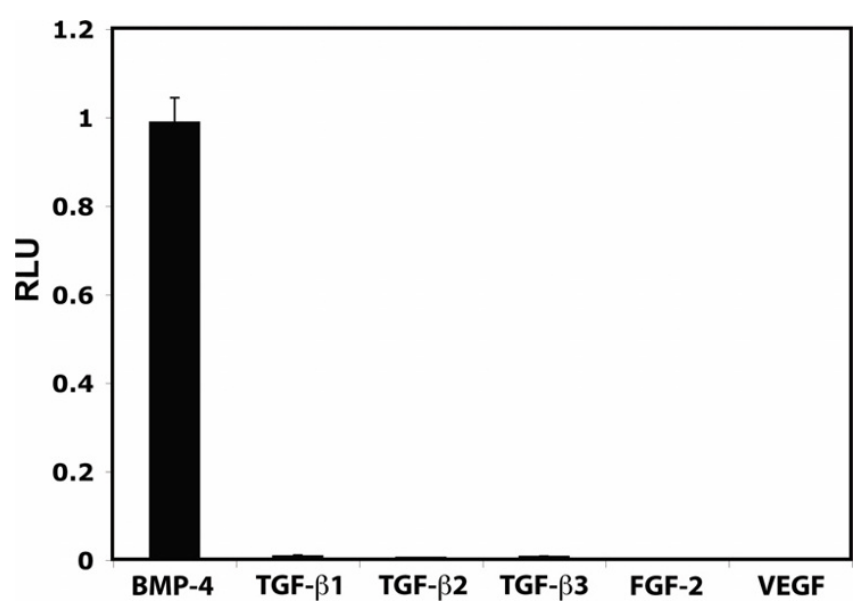

Figure 5

Effects of growth factors on the reporter-cell assay. C2CI2BRA cells were stimulated with Ing/ml (TGF- $\beta$ I, TGF- $\beta 2$ and TGF- $\beta 3$ ) or $10 \mathrm{ng} / \mathrm{ml}$ (FGF-2 and VEGF) of growth factors and the luciferase activity measured after 15 h. Treatment with I4 PM of rBMP-4 served as a positive control. Background luciferase level in the control sample (no BMP) was subtracted from each of the experimental values. The results are expressed as relative luciferase units (RLU). Each point represents the mean \pm SEM of triplicate wells from one representative experiment. Similar results were obtained in two separate experiments.

with an expression construct containing distinct sequence motifs derived from the mouse Id 1 promoter fused to a luciferase gene. When compared to other available cellbased bioassays or protein-based assays, our assay provides improved sensitivity for several BMP types, is faster, and is more specific for the measurement of BMP activity in complex biological solutions and in various biological situations.

Recently, another cell-based assay was described using C3H10T1/2 embryonic mouse cells stably transfected with the same reporter construct that we used in our assay [29]. Although the C3H10T1/2 assay can detect recombinant BMP-2 in DMEM-BSA at twofold lower concentration than our assay, our assay is more sensitive when measuring the activity of BMP-4 (3 pM compared to a concentration $>250 \mathrm{pM}$ ) and BMP-7 (125 pM compared to a concentration $>300 \mathrm{pM}$ ). Moreover, the sensitivity of the C3H10T1/2 assay was diminished when performed in the presence of large excess of foreign protein, i.e. concentrations of serum above $2 \%$. Although the sensitivity of HepG2BRA cells was also decreased by increasing concentration of serum, the ability of C2C12BRA cells to measure concentrations of recombinant BMP-4 as low as $7 \mathrm{pM}$ was not affected by concentrations of serum as high as $10 \%$. Thus, depending upon the biological medium to be assayed, one could use either C2C12BRA or HepG2BRA
A.

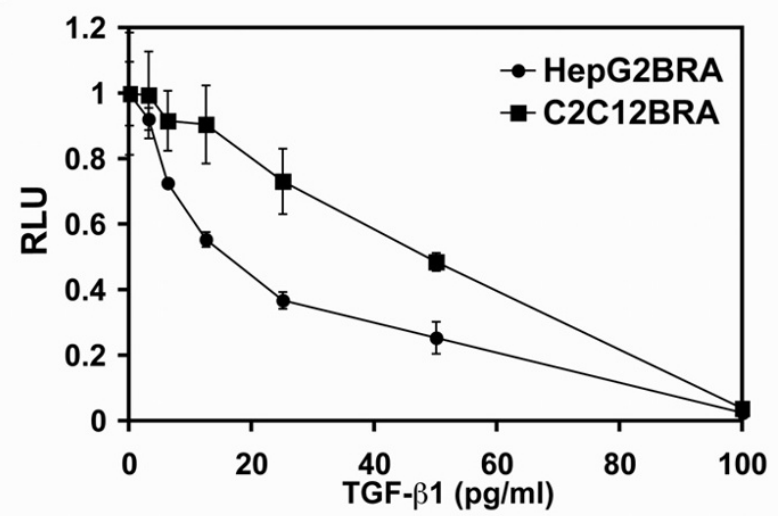

B.

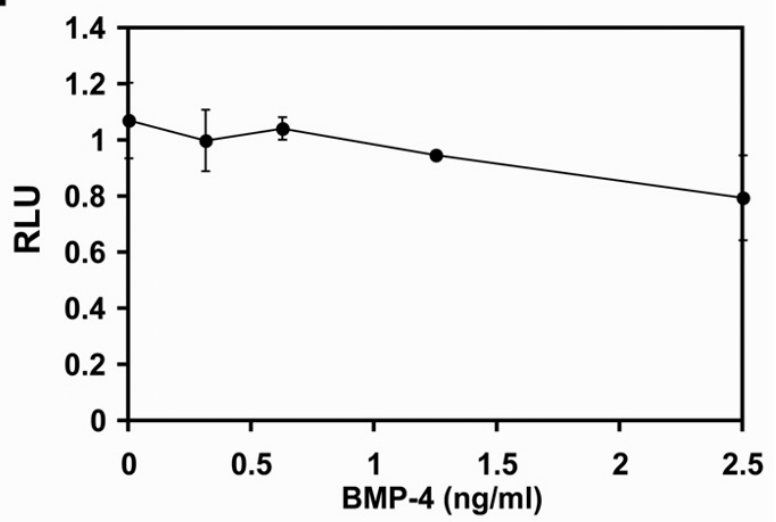

Figure 6

Effect of TGF- $\beta$ I on BMP-4 signaling pathway. (A) C2CI2BRA and HepG2BRA cells were treated with 14 PM of rBMP-4 in combination with increasing concentrations of TGF- $\beta$ I. After $15 \mathrm{~h}, \mathrm{BMP}$ activity was assessed by measuring luciferase activity in the cell lysates. Background luciferase level in the control sample (no BMP) was subtracted from each of the experimental values. The results are expressed as relative luciferase units (RLU) (the activity with 14 PM BMP-4 alone equal to one). (B) TGF- $\beta$-responsive reporter cells (TMLC) were stimulated with $250 \mathrm{pg} / \mathrm{ml}$ of TGF- $\beta$ I and increasing concentrations of BMP-4. After 16 h, TGF- $\beta$ I activity was assessed by measuring luciferase activity in the cell lysates. Each point represents the mean \pm SEM of triplicate wells from one representative experiment. Similar results were obtained in two separate experiments.

cells. Finally, we show how the assay sensitivity can be enhanced by cocultures of test cells and reporter cells.

Radioimmunoassays and enzyme linked immunoabsorbent assays (ELISA) are sensitive and specific and have been developed for BMPs [30,31]. The disadvantages of these assay are that they are expensive and that they measure both biologically active and inactive BMPs. Recently, a new protein based assay named ELIRA (enzyme-linked 


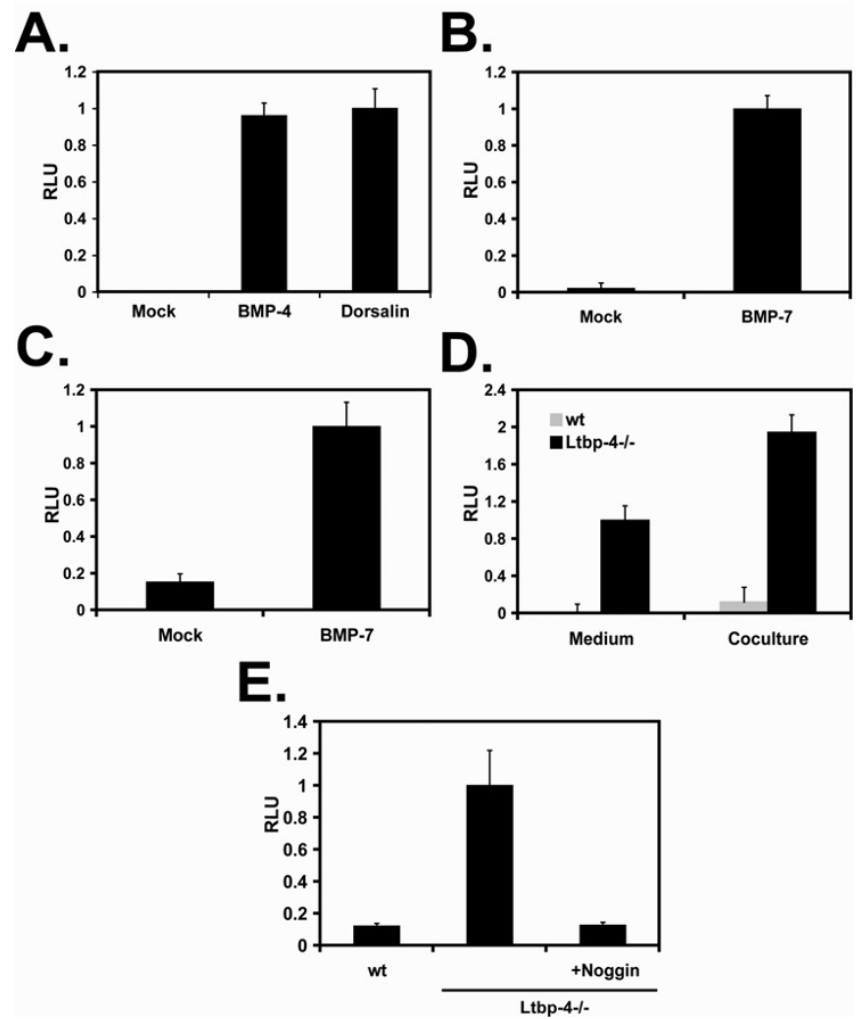

Figure 7

BMP activity measured in biological samples. (A) $4 \times$ $10^{3} \mathrm{C} 2 \mathrm{C} 12 \mathrm{BRA}$ cells/well were treated with supernatants of COS cells transfected with either a BMP-4 or a Dsl expression vector. Empty pcDNA3 plasmid was used as a mock control (B) $4 \times 10^{3} \mathrm{C} 2 \mathrm{Cl}$ 2BRA cells/well were treated with supernatants of $293 \mathrm{~T}$ cells transfected with the empty plasmid pcDNA3 (mock) or BMP-7 expression vector. (C) $4 \times$ $10^{3} \mathrm{C} 2 \mathrm{CI}$ 2BRA cells/well were cocultured with $4 \times 10^{3} 293$ cells/well stably transfected with a pcDNA3 (mock) or a BMP-7 expression plasmid. After $24 \mathrm{~h}$, luciferase activity was measured. (D) $4 \times 10^{3} \mathrm{C} 2 \mathrm{Cl} 2 \mathrm{BRA}$ cells/well were cocultured with I $\times 10^{4}$ wt or Ltbp-4 hypomorphic (Ltbp-4-/) lung fibroblasts. Luciferase activity was measured after $24 \mathrm{~h}$. Conditioned medium from the coculture was collected from wt and Ltbp-4-/ lung fibroblasts and applied to C2CI2BRA cells for $15 \mathrm{~h}$ to measure the amount of BMP activity. (E) $5 \times 10^{3}$ wt or Ltbp-4 hypomorphic (Ltbp-4-/-) lung fibroblasts were added to a 96 well plate. After $24 \mathrm{~h}, 4 \times 10^{3} \mathrm{C} 2 \mathrm{CI} 2 \mathrm{BRA}$ cells were added with or without $2 \mu \mathrm{g} / \mathrm{ml}$ of recombinant noggin. Luciferase activity was measured after $24 \mathrm{~h}$. The results are expressed as relative luciferase units (RLU). Each point represents the mean \pm SEM of triplicate wells from one representative experiment. Similar results were obtained in two separate experiments.

immunoreceptor assays) was developed for quantification of recombinant BMP-2 [32]. Although this assay measures the quantity of BMP-2 that binds to its recep- tors, this binding does not necessarily mean that the protein is biologically active. Our assay quantifies only BMP that is biologically active as opposed to immuno-reactive BMP. Moreover, the lower detection limit of the ELIRA was high ( 11 nM) compared to our assay and assay performance was disturbed by the presence of foreign proteins [32].

The differential sensitivity of C2C12BRA and HepG2BRA cells observed for different BMPs might be explained by the different expression patterns of endogenous BMPs and BMP receptors as characterized by RT-PCR (Fig. 1). Distinct BMPs have different effects depending on the nature, the absolute number and the different combinations of BMP type I and type II receptors on the cell surface [1]. The higher sensitivity of C2C12BRA cells compared to HepG2BRA cells when measuring BMP-4 activity might be due to the lower endogenous expression of BMP-4 in C2C12BRA cells compared to HepG2BRA cells (Fig. 1A). Although our assay is not BMP-isoform specific, the appropriate addition of neutralizing antibodies for a given BMP and the use of a standard curve should allow the quantification of specific biologically active BMPs.

As shown in Fig. 6A, whereas our assay is specific for BMP, luciferase expression induced by BMP can be affected by active TGF- $\beta$. To our knowledge, this is the first time that this observation has been made for this BMP reporter construct. Although TGF- $\beta$ does not have an effect on Id expression by itself, TGF- $\beta$ might indirectly modify the effect of BMP by sequestering Smad4 or induction of the expression of I-Smads $[19,20,22]$. TGF- $\beta$ activity measured with a TGF- $\beta$ reporter assay was not affected by recombinant BMP-4 (Fig. 6B). This is likely due to the lack of functional BMP-Smad pathway in these cells. Interestingly, the sensitivity of C2C12BRA for BMP-4 is only minimally affected by high concentrations of serum known to contain TGF- $\beta$ (Fig. 4B). This observation can be explained by the fact that TGF- $\beta$ in serum is in a latent form that must be activated in order to bind to its receptor and thus interfere with the BMP signaling pathway [33].

Beside its high sensitivity and specificity, another major advantage of our assay is the possibility to measure BMP activity from biological samples in a simple and efficient way. Quantification of BMP activity in complex biological solutions, as opposed to a defined medium, such as DMEM-BSA, is necessary for a cell-based assay to be useful to address specific problems related to BMP activity. In this paper, we describe the use of this assay in several ways to enhance its utility. First, we tested the possibility of this assay to measure BMP activity in non-defined medium. Our BMP reporter assay detected BMP activity in the conditioned medium of COS and 293T cells transfected with BMP-4 and BMP-7 expression plasmids, respectively (Fig. 
7A and 7B respectively). Interestingly, the amount of BMP activity detected in the conditioned medium was highly dependent on the cell line used to overexpress the specific BMP isoform. This might be due, as mentioned in previous studies, to the cell-specific expression pattern of proprotein convertases involved in the processing of the BMP inactive precursor form [34]. Second, C2C12BRA cells measure BMP activity when cocultured with 293 cells stably transfected with a BMP-7 expression vector (Fig. 7C). The advantage of this arrangement is that one can measure very low concentrations of BMP because of an increase in the local concentration of the cytokine without much dilution in the media. Third, this assay can measure endogenous BMP secreted by cells. Disruption of the Ltbp4 gene in mice results in abnormal lung development due to an enhanced activation of the BMP-4 signaling pathway both in vitro and in vivo [25]. Microarray analysis revealed that isolated $L t b p-4 \%$ lung fibroblasts from these mice express more BMP-4 and less of its inhibitor gremlin compared to wt cells [25]. Here we confirm these findings by showing that $L t b p-4 \%$ cells produce more BMP activity than wt cells (Fig. 7D). Interestingly, coculture of the BMP reporter assay cells with $L t b p-4 \%$ cells detected more BMP activity than when reporter cells were incubated with conditioned medium. This is probably due to an increase in the local concentration of BMP-4 without dilution of the cytokine in the media. The difference in luciferase activity between wt and $L t b p-4 \%$ cells was BMP-specific as the inclusion of noggin, a specific BMP inhibitor, in the coculture blocked the luciferase response induced by $L t b p-4-/$ - cells (Fig. 7E).

\section{Conclusion}

We have generated a rapid, specific and sensitive cellbased bioassay that can be used to measure BMP activity in complex solutions and in various biological contexts. Moreover, this bioassay can be used to study BMP signaling and to screen and identify new targets to modify BMP signaling pathways either positively or negatively.

\section{Methods \\ Cell lines and reagents}

C2C12, HepG2 (obtained from Dr. A. Kumar; New York University, NY), COS, 293, and 293T cells were grown in Dulbecco's Modified Eagle's Medium (DMEM) and supplemented with $10 \%$ fetal calf serum and antibiotics. Mink lung epithelial cells (TMLC) stably transfected with a plasmid containing the luciferase cDNA downstream of a TGF- $\beta$-sensitive portion of the plasminogen activator inhibitor 1 promoter were used as described [23]. Lung fibroblast cultures from adult wt and $L t b p-4 \%$ mice were obtained from Dr. K. Koli (University of Helsinki, Helsinki, Finland) and used as described [25]. 293 cells stably transfected with a BMP-7 expression vector have been previously described [35].
Recombinant human BMP-2, $-4,-6,-7$ and mouse noggin were purchased from $R \& D$ Systems Inc. Recombinant FGF-2 and VEGF were a gift from Dr. P. Mignatti (New York University School of Medicine, New York, NY 10016, USA).

pcDNA3 vector was obtained from Invitrogen (Carlsbad, CA, USA). The pMT21 expression vector containing Myctagged chick Dorsalin [24] was a gift from Dr. T. Jessell (Columbia University, NY). BMP-4 expression vector was a gift from Dr. A.H. Brivanlou (The Rockefeller University, $\mathrm{NY})$. pNeo-(BRE) ${ }_{2}$-Luc was generated by inserting a neomycin resistance gene into pGL3 (BRE) ${ }_{2}$-Luc vector [22].

\section{RNA extraction, reverse transcription and polymerase chain reaction (PCR)}

Total RNA was isolated from cells with Trizol (Invitrogen). cDNA was generated from RNA with reverse transcriptase and used as a template for amplification with Taq polymerase. Each PCR reaction consisted of initial denaturation at $94^{\circ} \mathrm{C}$ for $30 \mathrm{~s}$. The cycling parameters were as follows: $94^{\circ} \mathrm{C}$ for $30 \mathrm{~s}, 59^{\circ} \mathrm{C}$ for $45 \mathrm{~s}$ and $72^{\circ} \mathrm{C}$ for 1 min. After 25 cycles, reaction underwent a final extension at $72^{\circ} \mathrm{C}$ for $5 \mathrm{~min}$. Amplification products were electrophoresed on $1 \%$ agarose gels and visualized by ethidium bromide staining The primer sequences used for PCR amplification, based on published sequences, were as follows: 5'-TTTGGACCTGGCTAATGGAG-3' and 5'-GGCCACTTATTGTTGGCACT-3' for human ActR-IIa; 5'CTCCCTCACGGATTACCTCA-3' and 5'-AGGGCAGCATGTACTCATCC-3' for Human ActR-IIb; 5'-AATTGGCTTCTCGTTGCACT-3' and 5'-CATCTCCCAGATCCATGCTT-3' for mouse ActR-IIa; 5'-CATCATCACGTGGAACGAAC-3' and 5'-CTTGTGGACAACCACCTCCT-3' for mouse Act-RIIb; 5'CCTTGGATGAGCGTCCAGTTG-3' and 5'AGCCGAGCCTCTGCATC-3' for BMPR-II; 5'-AGACACTCCAGTACCCAGCTG-3' and 5'-GCTGTGAGTCTTGCGGATGG-3' for ALK-2; 5'-TGGTTCAGCGAACTATTGCCA-3' and 5'-TCAGCCATGATGTAGGGCTGG-3' for ALK-3; 5'AGTGGATCAGGCCTCCCTCGC-3' and 5'-CACTTCTGGAGGCATATAGCG-3' for ALK-6; 5'-ACTTCCAGAGATGAGTGGGA-3' and 5'-ATCTTGGTGCAAAGACCTGCT-3' for mouse BMP-2; 5'-ACTACCAGAAACGAGTGGGA-3' and 5'ATCTTGGTGCAAAGACCTGCT-3' for human BMP-2; 5'CAGATGTTTGGGCTGCGCC-3' and 5'-AGGTGAGTCACCTCAATGGC-3' for BMP-4; 5'-TTCCTCAACGACGCGGACAT$3^{\prime}$ and 5'-CCACCATGAAGGGCTGCTT-3' for BMP-6; 5'TGGACCTGTACAACGCCATG-3' and 5'-TGGTTGCTGGTGGCTGTGAT-3' for BMP-7. 5'-ACCACAGTCCATGCCATCAC-3' and 5'-TCCACCACCCTGTTGCTGTA-3' for G3PDH.

\section{TGF- $\beta$ bioassay}

To measure TGF- $\beta$ activity, TMLC cells in 96 wells were incubated with recombinant protein diluted in serum-free DMEM-0.1\% BSA. Sixteen hours later, TGF- $\beta$ was assessed 
by measuring luciferase activity in cell lysates as described previously [23]. All experiments were done in triplicate and repeated at least two times with similar results.

\section{Cell transfection}

COS and 293T cells were transiently transfected in 6-well dishes with $1 \mu \mathrm{g}$ of DNA per well using Lipofectamine Plus. After $16 \mathrm{~h}$, the medium was changed to serum-free OptiMEM (GIBCO BRL) and conditioned for $24 \mathrm{~h}$. Conditioned medium was precleared by centrifugation and tested in the BMP reporter assay.

To generate BMP reporter cells, C2C12 and HepG2 cells were stably transfected with pNeo-(BRE) ${ }_{2}$-Luc. Briefly, HepG2 and C2C12 cells were seeded at $8 \times 10^{4}$ cells/well in $35 \mathrm{~mm}$ dish for $24 \mathrm{~h}$ at which point they were transfected with $1 \mu \mathrm{g}$ of pNeo-(BRE) ${ }_{2}$-Luc DNA using Lipofectamine. Twenty-four hours later, cells were reseeded at different densities and selected for antibiotic resistance using $700 \mu \mathrm{g} / \mathrm{ml}$ geneticin. The resistant colonies were isolated, expanded, and tested in reporter cell assays. Clone 9 for C2C12 (named C2C12BRA) and clone 15 for HepG2 (named HepG2BRA) were found to be the most sensitive upon stimulation with recombinant BMP-4.

\section{BMP bioassay and BMP co-culture bioassay}

Unless indicated, the BMP assay was performed as follows: C2C12BRA and HepG2BRA cells were added to 96well plates culture dishes at $4 \times 10^{3}$ cells/well and $5 \times 10^{3}$ cells/well, respectively. The cells were allowed to attach overnight. The medium was replaced with the indicated medium containing the recombinant protein to be tested for BMP activity. After $14 \mathrm{~h}$, cells were washed twice with PBS and cell extracts were prepared with $45 \mu \mathrm{l}$ of $1 \times$ cell lysis buffer (BD Pharmingen). $35 \mu \mathrm{l}$ of the lysate was transferred to a 96-well microplate and assayed for luciferase activity using a LUMIstar Galaxy luminometer (BMG Labtechnologies). Luciferase activity was reported as relative luciferase units (RLU). The response of the cells to BMPs remained constant for at least 10 passages. When cells reached the $10^{\text {th }}$ passage, they were replaced with cells recovered from a frozen early passage stock.

For co-culture experiments, test cells were added at the densities indicated (see figure legends) in 96-well plates and allowed to attach overnight. $4 \times 10^{3} \mathrm{C} 2 \mathrm{C} 12 \mathrm{BRA}$ cells/ well were seeded on top and allowed to attach. Wells were washed once with PBS and incubated with $100 \mu \mathrm{l}$ of DMEM supplemented with $10 \%$ FBS. After 24 h, luciferase activity in cell extracts was measured. All results are expressed as relative luciferase unit (RLU), which is the value of the raw luciferase activity minus the background, in order to eliminate variations in calculations of fold induction due to differences in the background (no BMP) values between experiments. All assays were performed in triplicate and repeated at least two times with similar results.

\section{Abbreviations}

ActR, activin receptor; ALK, activin like receptor kinase; BMP, bone morphogenetic protein; FGF-2, basic fibroblast growth factor; VEGF, vascular endothelial growth factor; TGF- $\beta$, transforming growth factor- $\beta$; LTBP, latent TGF- $\beta$ binding protein; Id, inhibitor of differentiation; rBMP, recombinant BMP; BMPR, BMP receptor; Bre-Luc, $\mathrm{BMP}$ responsive element-luciferase; RT-PCR, reverse transcriptase - polymerase chain reaction; DMEM, Dabecco's modified Eagle's medium; ALP, alkaline phosphatase; TMLC, mink lung epithelial cells with a PAI-luciferase vector; PAI-1, plasminogen activator inhibitor 1; G3PDH, glycocaldehyde 3 phosphate dehydrogenase.

\section{Competing interests}

The author(s) declare that there are no competing interests.

\section{Authors' contributions}

LZ carried out all the experiments, coordinated and designed experiments, analysed data and prepared the manuscript. PtD and LS provided expert advice, provided reagents, and participated in the revisions of the manuscript. DBR conceived of the study, participated in its design and edited the manuscript. All authors read and approved the final manuscript.

\section{Acknowledgements}

This work was supported by NIH grant AR 49698 to DBR and LYS. LZ was a fellow of the Fondation pour la recherche medicale (FRM). PtD was supported by the Netherlands Organization for Scientific Research, and LYS by Shriners Hospitals for Children.

\section{References}

I. Shi Y, Massague J: Mechanisms of TGF-beta signaling from cell membrane to the nucleus. Cell 2003, I I3(6):685-700.

2. ten Dijke P, Korchynskyi O, Valdimarsdottir G, Goumans MJ: Controlling cell fate by bone morphogenetic protein receptors. Mol Cell Endocrinol 2003, 2 I I( I-2): I05-I I 3.

3. Sampath TK, Reddi AH: Dissociative extraction and reconstitution of extracellular matrix components involved in local bone differentiation. Proc Natl Acad Sci U S A 198I, 78( I 2):7599-7603.

4. Wozney JM, Rosen V, Celeste AJ, Mitsock LM, Whitters MJ, Kriz RW, Hewick RM, Wang EA: Novel regulators of bone formation: molecular clones and activities. Science 1988, 242(4885): 1528-1534.

5. Hogan BL: Bone morphogenetic proteins in development. Curr Opin Genet Dev 1996, 6(4):432-438.

6. Howe JR, Bair JL, Sayed MG, Anderson ME, Mitros FA, Petersen GM, Velculescu VE, Traverso G, Vogelstein B: Germline mutations of the gene encoding bone morphogenetic protein receptor IA in juvenile polyposis. Nat Genet 200I, 28(2): $184-187$.

7. Lories RJ, Luyten FP: Bone morphogenetic protein signaling in joint homeostasis and disease. Cytokine Growth Factor Rev 2005, 16(3):287-298.

8. Sneddon JB, Zhen HH, Montgomery K, van de Rijn M, Tward AD, West R, Gladstone H, Chang HY, Morganroth GS, Oro AE, Brown PO: Bone morphogenetic protein antagonist gremlin $I$ is widely expressed by cancer-associated stromal cells and can 
promote tumor cell proliferation. Proc Natl Acad Sci U S A 2006, 1 03(40): | 4842- | 4847.

9. Song $Y$, Jones JE, Beppu H, Keaney JF Jr., Loscalzo J, Zhang YY: Increased susceptibility to pulmonary hypertension in heterozygous BMPR2-mutant mice. Circulation 2005, I I 2(4):553-562.

10. Yanagita M: Modulator of bone morphogenetic protein activity in the progression of kidney diseases. Kidney Int 2006, 70(6):989-993.

II. Cui Y, Jean F, Thomas G, Christian JL: BMP-4 is proteolytically activated by furin and/or PC6 during vertebrate embryonic development. Embo J 1998, I7(16):4735-4743.

12. Sampath TK, Maliakal JC, Hauschka PV, Jones WK, Sasak H, Tucker RF, White KH, Coughlin JE, Tucker MM, Pang RH, et al.: Recombinant human osteogenic protein-I (hOP-I) induces new bone formation in vivo with a specific activity comparable with natural bovine osteogenic protein and stimulates osteoblast proliferation and differentiation in vitro. J Biol Chem 1992, 267(28):20352-20362.

13. Wang EA, Rosen V, D'Alessandro JS, Bauduy M, Cordes P, Harada T, Israel DI, Hewick RM, Kerns KM, LaPan P, et al.: Recombinant human bone morphogenetic protein induces bone formation. Proc Natl Acad Sci U S A 1990, 87(6):2220-2224.

14. Attisano L, Wrana JL: Smads as transcriptional co-modulators. Curr Opin Cell Biol 2000, I 2(2):235-243.

15. Derynck R, Zhang $Y$, Feng XH: Smads: transcriptional activators of TGF-beta responses. Cell 1998, 95(6):737-740.

16. Massague J, Wotton D: Transcriptional control by the TGFbeta/Smad signaling system. Embo / 2000, 19(8): I745-I 754.

17. Miyazono K, ten Dijke P, Heldin CH: TGF-beta signaling by Smad proteins. Adv Immunol 2000, 75: I I5-I57.

18. Balemans W, Van Hul W: Extracellular regulation of BMP signaling in vertebrates: a cocktail of modulators. Dev Biol 2002, 250(2):23।-250.

19. Candia AF, Watabe T, Hawley SH, Onichtchouk D, Zhang Y, Derynck R, Niehrs C, Cho KW: Cellular interpretation of multiple TGFbeta signals: intracellular antagonism between activin/BVg I and BMP-2/4 signaling mediated by Smads. Development 1997, I 24(22):4467-4480.

20. Maeda S, Hayashi M, Komiya S, Imamura T, Miyazono K: Endogenous TGF-beta signaling suppresses maturation of osteoblastic mesenchymal cells. Embo J 2004, 23(3):552-563.

21. Katagiri T, Yamaguchi A, Komaki M, Abe E, Takahashi N, lkeda T, Rosen V, Wozney JM, Fujisawa-Sehara A, Suda T: Bone morphogenetic protein-2 converts the differentiation pathway of C2CI 2 myoblasts into the osteoblast lineage. J Cell Biol 1994, I 27(6 Pt I): I755- 1766.

22. Korchynskyi O, ten Dijke P: Identification and functional characterization of distinct critically important bone morphogenetic protein-specific response elements in the Id I promoter. J Biol Chem 2002, 277(7):4883-489I.

23. Abe M, Harpel JG, Metz CN, Nunes I, Loskutoff DJ, Rifkin DB: An assay for transforming growth factor-beta using cells transfected with a plasminogen activator inhibitor-l promoterluciferase construct. Anal Biochem 1994, 216(2):276-284.

24. Basler K, Edlund T, Jessell TM, Yamada T: Control of cell pattern in the neural tube: regulation of cell differentiation by dorsalin-I, a novel TGF beta family member. Cell 1993, 73(4):687-702.

25. Koli K, Wempe F, Sterner-Kock A, Kantola A, Komor M, Hofmann WK, von Melchner H, Keski-Oja J: Disruption of LTBP-4 function reduces TGF-beta activation and enhances BMP-4 signaling in the lung. / Cell Biol 2004, I67(I): I23-133.

26. Kaabeche K, Lemonnier J, Le Mee S, Caverzasio J, Marie PJ: Cblmediated degradation of Lyn and Fyn induced by constitutive fibroblast growth factor receptor-2 activation supports osteoblast differentiation. J Biol Chem 2004, 279(35):36259-36267.

27. Kinto N, Iwamoto M, Enomoto-Iwamoto M, Noji S, Ohuchi H, Yoshioka $H$, Kataoka H, Wada Y, Yuhao G, Takahashi HE, Yoshiki S, Yamaguchi A: Fibroblasts expressing Sonic hedgehog induce osteoblast differentiation and ectopic bone formation. FEBS Lett 1997, 404(2-3):319-323.

28. Rawadi G, Vayssiere B, Dunn F, Baron R, Roman-Roman S: BMP-2 controls alkaline phosphatase expression and osteoblast mineralization by a Wnt autocrine loop. J Bone Miner Res 2003, | 8(10): | 842-1853.
29. Logeart-Avramoglou D, Bourguignon M, Oudina K, Ten Dijke $P$, Petite $\mathrm{H}$ : An assay for the determination of biologically active bone morphogenetic proteins using cells transfected with an inhibitor of differentiation promoter-luciferase construct. Anal Biochem 2006, 349(1):78-86.

30. Dai J, Keller J, Zhang J, Lu Y, Yao Z, Keller ET: Bone morphogenetic protein-6 promotes osteoblastic prostate cancer bone metastases through a dual mechanism. Cancer Res 2005, 65(18):8274-8285.

3I. Dattatreyamurty B, Roux E, Horbinski C, Kaplan PL, Robak LA, Beck HN, Lein P, Higgins D, Chandrasekaran V: Cerebrospinal fluid contains biologically active bone morphogenetic protein-7. Exp Neurol 200I, I72(2):273-28I.

32. Wendler J, Hoffmann A, Gross G, Weich HA, Bilitewski U: Development of an enzyme-linked immunoreceptor assay (ELIRA) for quantification of the biological activity of recombinant human bone morphogenetic protein-2. J Biotechnol 2005, I I 9(4):425-435.

33. Grainger DJ, Mosedale DE, Metcalfe JC: TGF-beta in blood: a complex problem. Cytokine Growth Factor Rev 2000, II(I2): $133-145$.

34. Constam DB, Robertson EJ: Regulation of bone morphogenetic protein activity by pro domains and proprotein convertases. J Cell Biol 1999, I 44(I): I39-149.

35. Gregory KE, Ono RN, Charbonneau NL, Kuo CL, Keene DR, Bachinger HP, Sakai LY: The prodomain of BMP-7 targets the BMP-7 complex to the extracellular matrix. J Biol Chem 2005, 280(30):27970-27980.

Publish with Bio Med Central and every scientist can read your work free of charge

"BioMed Central will be the most significant development for disseminating the results of biomedical research in our lifetime. "

Sir Paul Nurse, Cancer Research UK

Your research papers will be:

- available free of charge to the entire biomedical community

- peer reviewed and published immediately upon acceptance

- cited in PubMed and archived on PubMed Central

- yours - you keep the copyright

Submit your manuscript here:

http://www.biomedcentral.com/info/publishing_adv.asp
BiolMedcentral 